
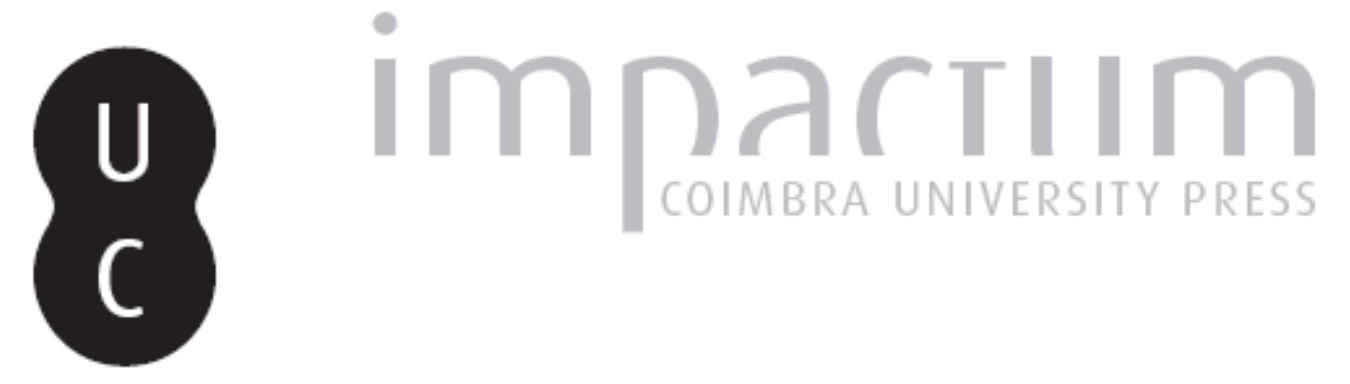

\title{
Grandes Heroínas Trágicas (7): Creúsa, no Íon de Eurípides
}

Autor(es): $\quad$ Silva, Maria de Fátima

Publicado por: Associação Portuguesa de Estudos Clássicos; Instituto de Estudos

URL

persistente:

URI:http://hdl.handle.net/10316.2/30303

DOI:

DOI:http://dx.doi.org/10.14195/0872-2110_57_1

Accessed : $\quad$ 26-Apr-2023 13:32:33

A navegação consulta e descarregamento dos títulos inseridos nas Bibliotecas Digitais UC Digitalis, UC Pombalina e UC Impactum, pressupõem a aceitação plena e sem reservas dos Termos e Condições de Uso destas Bibliotecas Digitais, disponíveis em https://digitalis.uc.pt/pt-pt/termos.

Conforme exposto nos referidos Termos e Condições de Uso, o descarregamento de títulos de acesso restrito requer uma licença válida de autorização devendo o utilizador aceder ao(s) documento(s) a partir de um endereço de IP da instituição detentora da supramencionada licença.

Ao utilizador é apenas permitido o descarregamento para uso pessoal, pelo que o emprego do(s) título(s) descarregado(s) para outro fim, designadamente comercial, carece de autorização do respetivo autor ou editor da obra.

Na medida em que todas as obras da UC Digitalis se encontram protegidas pelo Código do Direito de Autor e Direitos Conexos e demais legislação aplicável, toda a cópia, parcial ou total, deste documento, nos casos em que é legalmente admitida, deverá conter ou fazer-se acompanhar por este aviso.






\section{Boletim de Estudos Clássicos}

Associação Portuguesa de Estudos Clássicos Instituto de Estudos Clássicos

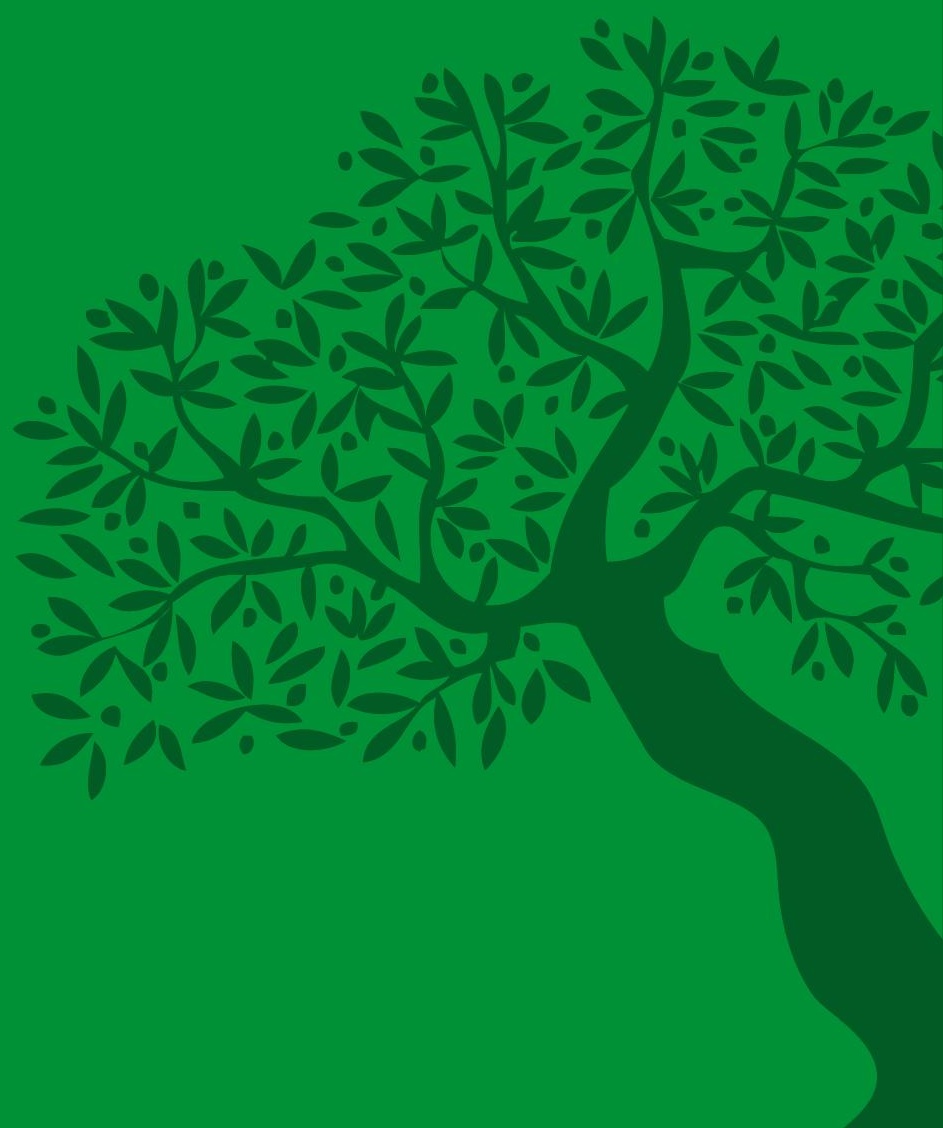

Coimbra

Junho de 2012 


\section{GRANDES HEROÍNAS TráGICAS (7)}

\section{Creúsa, no Íon de Eurípides}

Apresentada em ano próximo do final da campanha da Sicília (c. 413411 a. C.), o Íon é, sob uma superfície romanesca e aventurosa, o balanço do destino de Atenas, estabelecido por um contraste entre a elevação da sua origem mítica e o impasse da crise contemporânea. Entre esses dois limites, o poeta procura inquirir as tensões do momento e garantir, à cidade gloriosa, um futuro condigno, sob a forma simbólica de um herdeiro, continuador legítimo do passado e promessa de um futuro auspicioso. Apolo é, na criação de Eurípides, a mão que conduz e salva uma criança, de origem irregular e obscura, a própria encarnação dos Erectidas, os senhores de Atenas, e a instala à sombra protectora do seu templo, à espera da hora da revelação, que é também a do regresso à normalidade. É este um deus superior, que, aos agentes humanos da acção, 'conduz o destino, pois, apesar das aparências, nada acontece sem a sua intervenção' (67-68).

Em contraste com o reduto ideal que Delfos representa, onde Humanidade e deuses encontram um ponto de contacto, é dado espaço à crise em que vive a sociedade humana, que simbolicamente se centra numa mulher, Creúsa, a representante de uma linhagem em dificuldades de continuação, a casa real dos Erectidas, em Atenas. Se perspectivado como um drama ateniense, o Íon tem o seu eixo central na figura da princesa da cidade: filha de Erecteu, amante de Apolo, esposa de Xuto, mãe de um bastardo de semente divina, Íon, vítima de uma aparente esterilidade, a consulente do oráculo de Delfos acumula em sua volta a teia das linhas vitais da acção, que são, ao mesmo tempo, os alicerces da condição feminina ateniense, com repercussão na sobrevivência e futuro político da polis; na estrutura dramática, é também nela que se concentra o sofrimento da ruptura: é Creúsa quem está, ao mesmo tempo, presa às convenções do passado e quem aprende pelo sofrimento a construir uma nova ordem.

É como herdeira da primeira família de Atenas, que Creúsa vive o seu conflito pessoal. Sobre ela impende um dever elementar como detentora de um património, doméstico e político no seu caso: o de garantir, à casa de 
Erecteu e à cidade de Atenas, um herdeiro legítimo. O recuo à tradição mítica da polis ateniense demonstra, como uma prática repetida de geração em geração, a transmissão do património através de uma linhagem feminina (2026, 267-274). O nascimento de Erictónio marca uma etapa simbólica neste processo. Provindo do solo como legítimo 'filho da Terra', Erictónio foi entregue ao abandono num cesto que fez dele um filho sem pais e uma criança rejeitada à sua sorte. Desse destino salvou-o a deusa Atena que, oculto num cesto, o confiou à primogénita de Cécrops, soberano mítico do lugar. A curiosidade culpada da jovem Pandrosso, a princesa, persuadida pelas irmãs a abrir o cesto e a observar-lhe o conteúdo - além do recémnascido, duas serpentes que deviam protegê-lo -, contra a determinação da deusa, condenou à morte as três filhas de Cécrops e Aglauro e deixou, sem herdeiro directo, o bastião da Acrópole. Para assinalar o vínculo entre as mães de Atenas e a sua deusa padroeira, salvadora de Erictónio e garantia de um continuador, criou-se o costume de oferecer aos recém-nascidos uma serpente de ouro como marca de origem, legitimidade e vínculo à polis. Uma outra geração mítica da casa real ateniense conheceu experiência similar; em nome dos interesses da pátria invadida por estranhos, Erecteu dispôs-se a imolar as filhas; só Creúsa, 'protegida pelos braços maternos' (280), sobreviveu e, com ela, um vazio de poder e o encargo de conseguir um herdeiro para uma coroa abandonada.

Deste mito fundador, Atenas manteve uma tradição que, ao tempo em que Eurípides compunha a sua peça, gozava de grande simbolismo. Empenhada em demonstrar, perante o mundo helénico, um ascendente que lhe conferisse a legitimidade de ser cabeça de um império, agora que o perigo persa parecia arredado, a cidade de Palas revia-se, com orgulho, na sua autoctonia. Ser autóctone passou a significar - no decurso do séc. V a. C. não só viver, de há tempos imemoriais, no mesmo território, como até, simbolicamente, ter nascido das entranhas do próprio solo que se habita. Enquanto povos migrantes procuravam ainda um rumo e um local para se estabelecerem, já os autóctones perseguiam uma trajectória de desenvolvimento e progresso. Por isso, regressando à ficção dramática, Creúsa corporiza o dever de dar a Atenas um herdeiro com a legitimidade de um autóctone.

Em termos míticos, Creúsa encarna as dificuldades e contingências dessa autoctonia. É evidente, a um só olhar, a nobreza de raça de que é portadora (237-240); o aspecto coincide nela com uma natureza superior. É filha de Erecteu e a sua terra de origem é a cidade de Atenas (260-261). Por 
este mesmo ascendente, Creúsa é a imagem viva das tradições de Atenas, de quem se espera o cumprimento de uma obrigação: a de dar um herdeiro à sua casa e um soberano à cidade.

O casamento com um autóctone como condição desse desempenho, inclui, porém, no seu caso, uma perturbação manifesta. A sua primeira experiência matrimonial consumou-se por uma violação, a que não faltou violência. Nos recessos de uma gruta, oculta nas encostas da Acrópole, Apolo uniu-se à filha de Erecteu, produzindo, por umas bodas (10-11) consumadas à força, uma maternidade indesejada (946-949). O deus délfico, na peça o elo de ligação entre o mundo sacro e o humano, em Atenas comete 'um delito', forçando uma união 'irregular' com a filha de Erecteu, ou seja, penetrando a autoctonia ateniense com um toque do universal que o deus representa. Parece difícil, na sociedade que Eurípides conhece, aceitar como boa esta relação. Mas 'à força', o transgressor divino propõe-se simplesmente iluminar o caminho dos homens.

$\mathrm{O}$ abandono que condenou o bastardo assim nascido denunciou a leitura que Creúsa fez desta experiência. Antes de mais, entendeu a princesa renegálo e condená-lo à morte, temerosa da reacção que os pais, e a sociedade em sua volta, fariam desse encontro. Mais tarde, o mesmo segredo se lhe impôs perante o marido, que afinal, sem hesitação, se veio a orgulhar de um bastardo que também ele tivera de uma relação esporádica e que parecia gozar da compreensão geral (862-876). É essa dissimetria no tratamento social o que exige a Creúsa a confissão do seu delito, que durante anos tinha mantido oculto. Afinal, em vez de culpada, a mulher violada é uma vítima, da própria fragilidade (887-902). Mesmo se alguma culpa lhe pode ser imputada, a Apolo, o amante irreverente, igual culpa deve ser atribuída (960). A opinião pública, no entanto, não premeia igualmente os dois agentes da história. Poupando a violência masculina a qualquer reprovação, é contra a condição da mulher que as censuras se voltam, homens e deuses apostados na mesma incompreensão (878-880). Daí a legitimidade do lamento de que Creúsa se faz porta-voz (398-400): 'Bem difícil é a condição da mulher se comparada à do homem. Com as más confundem-se as honestas, num ódio comum. Foi para sofrer que nos criou a natureza'.

Todo este sofrimento humano não foi, porém, suficiente para apagar um impulso eugenes de que a princesa de Atenas era dotada. Ao abandonar a criança nascida desta união espúria e indesejada, ei-la que retomava, mesmo se com intenção condenatória, os mesmos gestos com que outrora a deusa Atena salvara Erictónio. Escondido num cesto, o filho de Apolo foi rodeado 
de um amuleto, a serpente de ouro protectora (15-21), além de uma coroa de oliveira da deusa e de um tecido, onde as mãos maternas tinham bordado uma Górgona, o monstro que Atena tinha vencido e de que exibia a pele, na égide, seu troféu de vencedora (1417-1436). Com estes objectos, Creúsa dava, à criança abandonada, uma identidade inconfundível: a de um verdadeiro ateniense, que mantinha, no acto de nascer, a tradição dos seus antepassados.

Embora garantindo, de forma inconsciente ou involuntária, o reconhecimento e a salvação do seu herdeiro, detentor de uma linhagem agora 'documentada', a princesa não pôde, mesmo assim, poupar o filho às penas da bastardia. A própria Pítia que, por desígnio de Apolo, o recolheu nos degraus do templo de Delfos, deu voz à surpresa humana perante uma ocorrência que lhe parecia sacrilégio ou atentado contra o nomos. Seguiu-se, apesar da protecção de Apolo, o percurso de vida de uma criança que nasceu sem pais (49-50) e, por isso, privada do afecto que a relação de paternidade comporta (1369-1379, 1489-1496).

Não ficou apenas pela violação o destino sofrido de Creúsa. Na ignorância desta experiência dolorosa, o soberano de Atenas e seu pai condenou-a ao casamento com um estrangeiro, Xuto, um aqueu; apesar de descendente de Zeus, este noivo representou para a princesa a humilhação de umas bodas desequilibradas com o seu estatuto e o risco de gerar uma descendência incapaz de satisfazer a exigência de uma casa real autóctone (57-64). Numa palavra, mesmo se legítimo, este matrimónio representava para a filha de Erecteu uma tremenda humilhação. Xuto, a par de Apolo e por diferentes razões, constitui, na opinião comum dos que observam o seu consórcio com a herdeira de Atenas, motivo de opróbrio pessoal e de instabilidade doméstica e política. De resto, Eurípides introduz na caracterização do marido de Creúsa elementos que convêm ao soldado, bem sucedido com certeza, mas um pouco bruto e boçal nas relações humanas. Ao contrário do que acontece com Creúsa, a reacção que um primeiro encontro de Xuto com Íon provoca é de rejeição e antipatia intuitivas. O entusiasmo do marido da princesa pelo encontro de um filho inesperado, por que tanto ansiava - o primeiro que encontrasse ao sair do tempo, rezava o oráculo -, leva-o a esquecer outras reflexões sobre quem fosse a mãe, quais as circunstâncias deste nascimento e, sobretudo, a reacção previsível da esposa estéril que o acompanhava a Delfos. Por isso os acontecimentos o penalizam, mantendo-o no desconhecimento da verdade e reduzindo-o a um mero instrumento dos desígnios de Apolo. 
Na perspectiva mítica, as duas uniões de Creúsa, com um deus primeiro e com um descendente de Zeus depois, são dignas e honrosas; mas se encaradas numa perspectiva política, são ilegítimas face ao código legal estabelecido e igualmente inaceitáveis. A partir deste pressuposto, os códigos de parentesco sofrem também uma distorção; o filho nascido de Apolo é um bastardo, repudiado pela mãe e confiado à guarda paterna; de Xuto, a própria natureza parece recusar um herdeiro, antes de um processo de esclarecimento que Apolo se encarrega de promover. Estes são os elementos essenciais do conflito que alimenta o Íon e que confluem na personalidade central, a filha de Erecteu.

O simbolismo de novo se apropria da cena, através de uma esterilidade incompreensível que penaliza este casal (304). Não é da união com um estrangeiro que se espera um herdeiro pleno para Atenas; como também, nem o filho de Apolo detém, para esse propósito, uma legitimidade incontroversa. A situação atingiu, portanto, um impasse, que uma consulta ao oráculo délfico tem por objectivo resolver. É duplo o motivo dessa consulta: o esclarecimento que um casal sem filhos espera do deus sobre a esterilidade que a ambos penaliza; ao mesmo tempo que Creúsa aguarda uma outra clarificação, que lhe revele o paradeiro do filho outrora gerado com a participação do deus. Eurípides deixa claro, como um novo calvário a percorrer pela sua heroína, as penas da esterilidade para uma mulher casada, que vêm sobrepor-se às que afectam uma mãe solteira. Porque princesa, é em maior grau que a esterilidade afecta Creúsa; numa só pessoa impende a transmissão do património familiar e a segurança da cidade, oikos e polis entendidos como uma extensão um da outra (618-620).

Partindo do mítico para o puramente humano, o poeta psicólogo que Eurípides tende a ser avalia, no plano conjugal, a repercussão da mesma esterilidade. Uma informação imponderada, e falsa, que nada na acção da peça justifica - a de que a esterilidade de Creúsa é efectiva e irreversível tem uma utilidade dramática: a de levar ao extremo o desespero de uma mulher sem filhos, prestes a ser confrontada com a traição e abandono do marido (761-762). A frustração que a mulher estéril representa para o marido pode ser vivida em solidariedade conjugal, ou no isolamento da esposa (771772, 789-791). Grave se torna, porém, a penalização feminina, se o marido, às ocultas, procura satisfazer, fora do casamento, essa necessidade (695-708). Inspirado por um comportamento que reconhece como vulgar, o coro de mulheres atenienses, testemunha do inesperado encontro de um filho de Xuto, prevê para a sua senhora a condenação inevitável (676-680): 'Prevejo as 
lágrimas e os gritos de dor, prevejo os acessos de soluços, quando a minha rainha souber que o marido goza da alegria de ser pai, enquanto ela ficará estéril e sem descendência'.

No plano mítico, Creúsa acumula motivos de censura contra o deus de Delfos; apesar de estar em dívida para com a jovem que outrora violou, Apolo parece agravar esta humilhação com a dádiva de um filho apenas a Xuto. Recapitulando, de seguida, a outra etapa decisiva no seu percurso feminino - o casamento com Xuto -, também os agravos se aprofundam; a união com um estrangeiro parece revelar inconvenientes cada vez mais notórios. Este filho oculto representa mais do que o abandono de uma esposa infeliz; acarreta traição contra uma casa real, que assim se vê prejudicada na sua pureza e expectativas. Como procede, à traição, o marido de uma mulher estéril? - comenta o velho Pedagogo. Não procura solidarizar-se com ela, na partilha do infortúnio. Trata, isso sim, de arranjar um filho às escondidas, da união ilícita com uma escrava; leva-o depois para fora de fronteiras, onde provê ao seu crescimento, para o recuperar, como herdeiro consumado, quando adulto (817-824). Sem negar, mesmo assim, o direito paterno a uma solução de continuidade, o Pedagogo enuncia o que poderia parecer à opinião pública uma solução sensata: a tentativa de persuadir a mulher, porque estéril, a aceitar um herdeiro, filho de uma mãe honrada e digna (839-841). Clara fica a ideia de que não restaria à visada outra alternativa que não aceitar, com dignidade, a proposta. Uma recusa da sua parte iria legitimar uma opção por outra esposa (841-842).

A crise progride com base em aparências e pressupostos; Creúsa tem a reacção, essa humana, própria de uma madrasta, encarnação da mulher atingida e ressabiada pelo fracasso da maternidade. Íon, que se julga o bastardo que Apolo prometera a Xuto, teme, com razão, o ressentimento furioso da que se tornará sua madrasta (607-615; cf. 1329); atrás virá o descalabro familiar, num lar onde o marido vive o conflito entre renegar um filho ilegítimo para agradar à mulher, ou pôr em causa a paz doméstica para impor a presença do seu bastardo.

Tão forte é, de facto, a reacção de Creúsa pelo insulto que esta novidade representa para a sua honra feminina, que se determina, ao fim de tantos anos, a revelar o nascimento do filho de uma relação com Apolo; antes aceitar a vergonha de uma violação do que o opróbrio da esterilidade. Os extremos de violência a que se propõe - a de se assumir como uma madrasta raivosa que não hesita em eliminar o bastardo (1269-1274), sem olhar sequer 
à santidade imaculada do recinto délfico -, tem por isso, a par da paixão excessiva da mulher, a legitimidade que cabe à herdeira de Atenas.

É o valor da autoctonia, com o seu ascendente tradicional, que Eurípides pretende pôr em causa, em tempos em que a crise contemporânea reveste os mesmos contornos da vivida pela mítica Creúsa: como encontrar, para uma cidade sem futuro à vista, um condutor firme e legítimo. Talvez esta característica, com que os Atenienses pretendiam afirmar tradição, mérito e superioridade, afinal parecesse, a quem a olhava do exterior, um valor decadente e incompreensível. Ainda que ateniense, Íon, por seu lado, não fizera o percurso de vida que o levaria ao reconhecimento da sua origem. Por isso a opinião que emite sobre Atenas é independente e isenta, mas crítica a propósito das dificuldades com que um estrangeiro pode ganhar na cidade, que se diz aberta e democrática, um lugar digno.

Se a condição de ateniense de Íon não for abonada pelos dois progenitores, ele está condenado a manter-se um estranho, face 'ao povo autóctone e glorioso de Atenas, puro de qualquer infiltração estrangeira' (589-590), sendo ele de resto, além de estrangeiro, um bastardo (591-592). $\mathrm{Na}$ avaliação negativa que o jovem faz da experiência democrática de Atenas, vai contida uma manifesta incompatibilidade entre o valor da autoctonia e o comportamento que se espera de uma cidade moderna, livre e cosmopolita.

É exactamente a conciliação harmoniosa de um passado ilustre com um futuro promissor para Atenas o que Apolo assegura com o milagre de um herdeiro, detentor da legitimidade genética e da clarividência apolínea. E fálo-á mau grado a incompreensão humana, submetida à aprendizagem que só o sofrimento permite. Chegada a hora climática no destino sofrido de Creúsa, quando, através de um veneno, dádiva da Górgona aos seus antepassados, ela ensaiava, na sua ignorância persistente, eliminar pela segunda vez aquele que julgava um inimigo, é então que os desígnios de Apolo se revelam e se cumprem. A cena enche-se das tensões que os homens, por inépcia, provocam. Íon olha a mulher que atentou contra a sua vida como para uma víbora (1261-1265), enquanto Creúsa invoca, para o seu crime falhado, a defesa intransigente da autoctonia ateniense.

A intervenção divina produz-se por etapas. É pela mão de Apolo que a Pítia, cumprida a sua trajectória de mãe apenas afectiva, repõe, entre mãe e filho, o cesto e, com ele, os meios de um reconhecimento. Deste cesto, em si mesmo simbólico, saem os sinais da legitimidade ateniense: a serpente de ouro que protegeu o primeiro filho do solo ático, Erictónio, e uma coroa de oliveira de Atena, árvore dos tempos primordiais em que os deuses 
disputaram a posse de Atenas. Fica assim sanada a dor moral da filha de Erecteu, que, ao mesmo tempo, julga conseguido o seu objectivo político, o de assegurar um herdeiro legítimo à cidade (1463-1467). Para isso, a princesa aceita manter Xuto na ilusão de ser pai, dado que nem o filho do deus teria direito à herança ateniense (1541-1543). Mas só Atena, numa aparição ex machina como procuradora do deus de Delfos, virá completar o apaziguamento final e iluminar plenamente aquele olhar que Creúsa enfim ergue, sem mágoa, para o sol.

É pela linhagem materna que Íon pode suceder, em Atenas, aos seus antepassados míticos. Mas o destino que os deuses lhe propõem é de tornar-se através dos seus sucessores, para além da estreiteza da autoctonia, em fundador epónimo da Iónia (1575-1588; cf. 74-75). Mais além vai ainda a previsão divina. O casal Creúsa e Xuto será também abençoado com dois herdeiros, Doro e Aqueu, por sua vez epónimos dos Dórios. E não se trata, apenas, de um final feliz para uma peça romanesca; na reconciliação de Creúsa com o deus oracular vai contida uma mensagem pan-helénica, que fará da princesa de Atenas a mãe dos fundadores iónios e dórios. Fica clara a proposta da peça: a de uma união entre os Gregos, onde a Atenas e a Esparta coubesse a iniciativa e a concretização. Sem deixar de valorizar a tradição como uma vantagem que dá ascendente, a mensagem da tragédia é aberta e universalista. Mas só um milagre, saído da imaginação feminina ou da superior clarividência de Apolo, parecia capaz de o conseguir.

MARIA DE FÁTIMA SILVA 